\title{
ESTIMATION OF PARAMETERS OF STATE OF CROPS AND SOIL ENVIRONMENT TO REMOTE SENSING DATA
}

Ilya Mikhailenko, Valeriy Timoshin

Agrophysical Research Institute, St. Petersburg, Russia

ilya.mihailenko@yandex.ru, timoshinv@yandex.ru

\begin{abstract}
An analysis of modern work in the field of the use of Earth remote sensing data in agriculture has shown that, at present, they have not yet created the information and methodological basis for estimating the parameters of the chemical state of plants and soil. Currently, sample surveys of fields with mechanical sampling at individual points at the end of the growing season are widely used. Such a survey is very time-consuming and expensive, and most importantly, does not have sufficient accuracy required to solve management problems and decision-making in precision farming. The aim of this work is to bridge this gap, which will make it possible to more fully use the modern capabilities of remote sensing of the Earth to solve many problems of agricultural technology management. Since the parameters of the chemical state of the soil are inaccessible to remote sensing, a two-stage iterative scheme for their assessment was developed. It consists in the fact that on the basis of mathematical models and current data of remote sensing of the Earth, the parameters of the crop biomass are estimated, as well as the parameters of the chemical state of the crop biomass, and estimates of the parameters of the chemical state of the soil are constructed from the estimates and the mathematical model. Moreover, the closure of this integration procedure is carried out by comparing the actual reflection parameters relative to the chemical state of the crop and their estimates obtained at the first stage of the assessment procedure.
\end{abstract}

Key words: control, estimation, biomass parameters, algorithm, mathematical models, chemical state, soil, remote sensing.

\section{Introduction}

Modern information technologies are components of "smart agriculture", which also includes remote data collection from the fields. Among the components of "smart agriculture", the central place is occupied by precision farming (PF) technologies, which include a complex of modern information technologies and robotic technological In essence, such a complex is aimed at solving the problems of managing agricultural technologies $[1 ; 2]$.

Application of mineral fertilizers is the operations through which crop yields are formed. At the same time, optimization of fertilizer doses is one of the central and not yet positively solved problems. Its solution is constrained by the lack of reliable information on the content of the main chemical elements of plant nutrition in the soil, i.e. about the parameters of the chemical state of the soil. Sample surveys of fields with mechanical sampling at individual points, carried out at the end of the growing season, is very difficult. Marks and roads, most importantly, do not have sufficient accuracy required to solve management and decision-making tasks. This situation makes it very relevant to use such high-performance modern monitoring tools as remote sensing of the Earth (ERS). However, despite the obvious progress in the use of remote sensing, there is a clear lag in the development of methods for using this information in support systems for managerial decision-making in PF. Here, methods for assessing the state of crops of crops based on various types of indices, which are combinations of reflection parameters on different channels of the optical spectrum, are most widely used today [3; 4]. Examples of the use of these indices can be found in many modern works [4-9]. Basically, methods associated with the use of vegetation indices were aimed at assessing the biomass value [10-13]. This is due to the fact that, in essence, vegetation indices are scalar quantities, which do not allow obtaining multicomponent information on them based on a larger number of parameters of the state of crops and soil environment necessary for making managerial decisions in PF.

At the same time, works have recently begun to appear that show a desire to use Earth remote sensing data to estimate some chemical parameters of plants in crops (nitrogen, carotenoids, chlorophyll, etc.) $[14 ; 15]$. Such a turn in the orientation of research seems very promising for a gradual transition to assessing the parameters of the soil-sowing system. In this regard, very interesting conclusions follow from the review work [16]. It shows the evolution of methods for using remote sensing data in precision farming for 25 years of development of this technological area. So. during this period there was a transition from the use of the simplest sensors of individual physical parameters of media to hyperspectral remote sensing data. This transition was accompanied by a significant 
increase in spatial resolution of images formed by remote sensing systems. Such new opportunities of modern remote sensing methods allow not only focusing on various normalized vegetation indices, but proceeding to the analysis of specific compounds, molecular interactions, stress loads and biophysical or biochemical characteristics of crops. This leads to significant interest in the multiple collection of remote sensing data to conduct real-time processing of soil, crops and pests [17].

In this direction, the work carried out by researchers of the Lausanne Federal Polytechnic School is of great interest, within which walls a small-sized multispectral receiver was developed, the mass of which allows it to be placed on an unmanned aerial vehicle (UAV) [18; 19]. In these works, it was shown that data on the spectral characteristics of plants obtained using a miniature hyperspectral imaging camera allow users quickly and with a high degree of reliability determine various indicators of the state of crops and thereby increase the efficiency of agricultural practices and land use and contribute to the implementation of the concept of PF.

As follows from the analysis of modern works in the field of the use of remote sensing in agriculture, information and methodological foundations for estimating the parameters of the chemical state of plants and soil based on remote sensing data have not yet been created. The aim of this work is to bridge this gap, which will make it possible to more fully use the modern capabilities of remote sensing tools to solve many management tasks in PF.

\section{Formulation of the problem}

Since the state of sowing biomass is available to remote sensing means, a two-stage procedure can be used to solve the problem of estimating the parameters of the chemical state of the soil. At the first stage, according to remote sensing data, the parameters of the state of the sowing biomass are evaluated immediately before harvesting, and at the second stage, based on the model of communication with the crop, the parameters of the chemical state of the soil are estimated [20-22]. Despite the apparent simplicity of this approach, it should be borne in mind that at the time of harvesting we evaluate not the current values of the parameters of the chemical state of the soil, but only their residual values. This is due to the fact that the nutrients themselves are carried out with the crop and rainfall throughout the growing season. The lack of information about these losses introduces significant uncertainty in the model of the dependence of the crop on the parameters of the chemical state. This forces us to move from the final (terminal) estimates to the current (monitoring) estimates formed over the entire interval of the growing season of the crop. Such a transition is possible only with a significant expansion of the number of optical remote sensing channels and mathematical models, on the basis of which it is possible to form monitoring estimates. So, the development of new multispectral means of remote sensing allows to obtain operational information about the parameters of the chemical state of crops associated with similar soil parameters. In Fig. 1, 2, 3 maps are shown of the nitrogen content of $\mathrm{N}$, potassium $\mathrm{K}$, and phosphorus $\mathrm{P}$ in corn plants at Kayapo Farm in Brazil. They were obtained by researchers at Gamaya [23] (Report on Kayapo Farm. June 2015), established at the Lausanne Federal Polytechnic School.

As it can be seen from these images, the main elements of plant nutrition have different spectral scales, which indicates the information content of the remote sensing channels used in relation to the chemical parameters of plants.

To use this information in the estimation problem, it is necessary to introduce two mathematical models. The first of these is a dynamic model that takes into account all the factors affecting the chemical parameters of plants. It is a source of a priori information on the chemical parameters of plants. The second model reflects the relationship of these parameters with the optical reflection in the blue, green and red ranges of the optical spectrum. This model is a source of posterior information on the chemical parameters of plants. It should take into account cross-links between optical channels. Given the fact that the parameters of the chemical state physically reflect the content of the chemical element $\left(\mathrm{g} \cdot \mathrm{kg}^{-1}\right)$, then in the complex of the models used, a model of the dynamics of the mass parameters of sowing over the field area will be required. To implement the procedure for assessing mass indicators of sowing, a model of the connection of these parameters with the optical reflection in the used remote sensing channels is also necessary. 


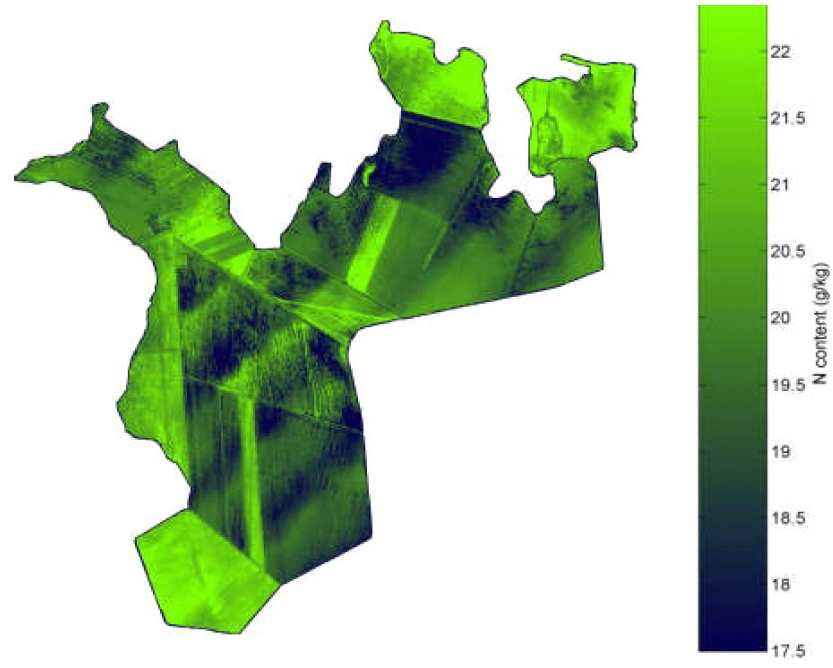

Fig. 1. Example of the distribution of spectral reflection parameters depending on the nitrogen content in the biomass of maize sowing

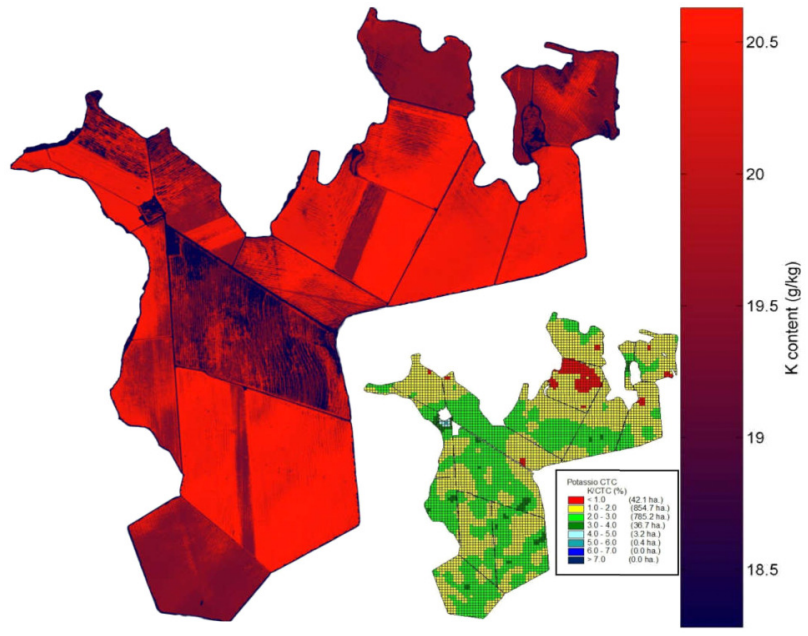

Fig. 2. Example of the distribution of the spectral reflection parameters depending on the potassium content in the biomass of corn sowing

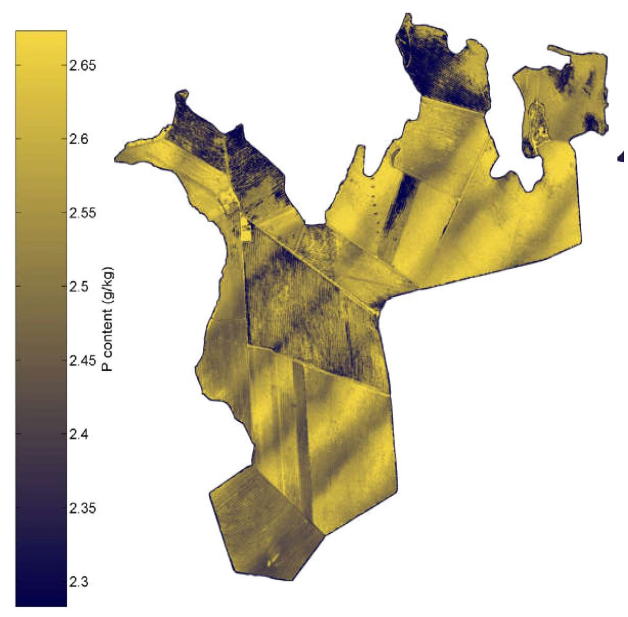

Fig. 3. Example of the distribution of spectral reflection parameters depending on the phosphorus content in the biomass of corn sowing 
Finally, to obtain the desired estimates of the chemical parameters of the soil, a dynamic model is still required, considering the direct and inverse relationship of these parameters with the parameters of the chemical state of the plants in the crop and with the mass indicators of the crop.

Thus, the construction of monitoring estimates of the parameters of the chemical state of plants and soil is possible only by modeling all the components of the soil - sowing system. This system includes the following mathematical models.

\section{Model of optical measurements of the state of crop biomass}

Due to the general physical laws of light reflection from an inhomogeneous dispersed medium, including crops, the measurement model can be represented in the following vector-matrix symbolic form [24]

$$
\mathrm{Y}_{\mathrm{X}}=\mathrm{pe}^{-\mathrm{PX}},
$$

where $\mathrm{p}-$ the vector of scale parameters;

$\mathrm{P}$ - the matrix of communication parameters between the sowing conditions and optical reflectance in the used spectral ranges;

$\mathrm{X}-$ the vector of sowing state parameters.

Due to the fact that estimating the parameters of an exponential model is difficult, due to its instability, it is advisable to use variants of models, where this function is expanded in a power series. For mass indicators of sowing, it has the following form [25]

$$
\begin{aligned}
& z_{1 m}=p_{10, m}+p_{11, m} x_{1 m}+p_{12, m} x_{2 m}+p_{13, m} x_{1 m}^{2}+p_{14, m} x_{2 m}^{2}+p_{15, m} x_{1 m}^{3}+p_{16, m} x_{2 m}^{3}, \\
& z_{2 m}=p_{20, m}+p_{21, m} x_{1 m}+p_{22, m} x_{2 m}+p_{23, m} x_{1 m}^{2}+p_{24, m} x_{2 m}^{2}+p_{25, m} x_{1 m}^{3}+p_{26, m} x_{2 m}^{3},
\end{aligned}
$$

or in the vector matrix character form

$$
\mathrm{Z}_{m}=\mathrm{P}_{m} \mathrm{~W}\left(\mathrm{X}_{m}\right),
$$

where $Z_{m}^{\mathrm{T}}=\left[\begin{array}{ll}z_{1 m} & z_{2 m}\end{array}\right]$ - vector of the average over the area of the field reflection parameters in the visible range $\left(z_{1 m}\right)$ and in the infrared range of the spectrum $\left(z_{2 m}\right)$; $\mathrm{P}_{m}=\left[\begin{array}{lllllll}p_{01} & p_{11} & p_{12} & p_{13} & p_{14} & p_{15} & p_{16} \\ p_{02} & p_{21} & p_{22} & p_{23} & p_{24} & p_{25} & p_{26}\end{array}\right]_{m}$ - matrix of model parameters; $\mathrm{W}\left(\mathrm{X}_{m}\right)=\left[\begin{array}{lllllll}1 & x_{1 m} & x_{2 m} & x_{1 m}^{2} & x_{2 m}^{2} & x_{1 m}^{3} & x_{2 m}^{3}\end{array}\right]$ - vector function, where the arguments are the parameters of the sowing state: $x_{1 m}$ is the average density of the sowing biomass over the field area (yield), $\mathrm{kg} \cdot \mathrm{m}^{-2} ; x_{2 m}$ is the average density of the wet mass of the crop over the area of the field, $\mathrm{kg} \cdot \mathrm{m}^{-2}$.

\section{Model of optical measurements of the chemical state of crop biomass}

It has the same shape as the model (2), but its dimension is determined by the number of parameters of the chemical state and the spectral ranges used

$$
\begin{aligned}
& z_{1 h}=p_{10}+p_{11} x_{1 h}+p_{12} x_{2 h}+p_{13} x_{3 h}+p_{14} x_{1 h}^{2}+p_{15} x_{2 h}^{2}+p_{16} x_{3 h}^{2}+p_{17} x_{1 h}^{3}+p_{18} x_{2 h}^{3}+p_{19} x_{3 h}^{3}, \\
& z_{2 h}=p_{20}+p_{21} x_{1 h}+p_{22} x_{2 h}+p_{23} x_{3 h}+p_{24} x_{1 h}^{2}+p_{25} x_{2 h}^{2}+p_{26} x_{3 h}^{2}+p_{27} x_{1 h}^{3}+p_{28} x_{2 h}^{3}+p_{29} x_{3 h}^{3}, \\
& z_{3 h}=p_{30}+p_{31} x_{1 h}+p_{32} x_{2 h}+p_{33} x_{3 h}+p_{34} x_{1 h}^{2}+p_{35} x_{2 h}^{2}+p_{36} x_{3 h}^{2}+p_{37} x_{1 h}^{3}+p_{38} x_{2 h}^{3}+p_{39} x_{3 h}^{3} .
\end{aligned}
$$

or in symbolic vector matrix form

$$
\mathrm{Z}_{h}=\mathrm{P}_{h} \mathrm{~W}\left(\mathrm{X}_{h}\right),
$$

where $\quad \mathrm{P}_{m}=\left[\begin{array}{cccccccccc}p_{10} & p_{11} & p_{12} & p_{13} & p_{14} & p_{15} & p_{16} & p_{17} & p_{18} & p_{19} \\ p_{20} & p_{21} & p_{22} & p_{23} & p_{24} & p_{25} & p_{26} & p_{27} & p_{28} & p_{29} \\ p_{30} & p_{31} & p_{32} & p_{33} & p_{34} & p_{35} & p_{36} & p_{37} & p_{38} & p_{39}\end{array}\right]_{m}$ - matrix of parameters; 
$\mathrm{W}^{\mathrm{T}}\left(\mathrm{X}_{h}\right)=\left[\begin{array}{llllllllll}1 & x_{1 h} & x_{2 h} & x_{3 h} & x_{1 h}^{2} & x_{2 h}^{2} & x_{3 h}^{2} & x_{1 h}^{3} & x_{2 h}^{3} & x_{3 h}^{3}\end{array}\right]$ - vector function of the parameters of the chemical state of the crop;

$z_{1 h}, z_{2 h}, z_{3 h}$ - reflection parameters in the blue, visible, and red channels relative to the parameters of the chemical state of plant biomass:

$x_{1 h}, x_{2 h}, x_{3 h}$ are the nitrogen, potassium, and phosphorus contents, respectively.

\section{Model of the dynamics of the state parameters of biomass}

It reflects the evolution of mass indicators of sowing in the daily time scale depending on the main influencing factors [26]

$$
\begin{aligned}
& {\left[\begin{array}{l}
\dot{x}_{1 \mathrm{~m}} \\
\dot{x}_{2 \mathrm{~m}}
\end{array}\right]=\left[\begin{array}{ll}
a_{11} & a_{12} \\
a_{21} & a_{22}
\end{array}\right]_{m}\left[\begin{array}{l}
x(t)_{1 \mathrm{~m}} \\
x(t)_{2 \mathrm{~m}}
\end{array}\right]\left[\begin{array}{llll}
b_{11} & b_{12} & b_{13} & b_{14} \\
b_{21} & b_{22} & b_{23} & b_{24}
\end{array}\right]_{m}\left[\begin{array}{l}
v_{N}(t) \\
v_{K}(t) \\
v_{P}(t) \\
v_{4}(t)
\end{array}\right]+} \\
& +\left[\begin{array}{lll}
c_{11} & c_{12} & c_{13} \\
c_{21} & c_{22} & c_{23}
\end{array}\right]_{m}\left[\begin{array}{l}
f_{1}(t) \\
f_{2}(t) \\
f_{3}(t)
\end{array}\right] \\
& t \in\left(T_{1}, T_{2}\right),
\end{aligned}
$$

In the block of parameters of the structure of biomass, the following states are:

- $x_{1 m}-$ the average density of sowing biomass over the field area (crop), $\mathrm{kg} \cdot \mathrm{m}^{-2}$;

- $x_{2 m}$ - field average density of the wet mass of the crop, $\mathrm{kg} \cdot \mathrm{m}^{-2}$;

- $f_{1}$ - external disturbances in both blocks- daily average air temperature, ${ }^{\circ} \mathrm{C}$;

- $f_{2}-$ the average daily radiation level, $\mathrm{W}\left(\mathrm{m}^{2} \cdot \mathrm{h}\right)^{-1}$;

- $f_{3}$ - the average daily rainfall intensity, $\mathrm{mm}$.

Parameters of the chemical state of the soil:

- $v_{N}$ - the nitrogen content in the soil, $\mathrm{kg} \cdot \mathrm{ha}^{-1}$;

- $v_{K}$ - the potassium content in the soil, $\mathrm{kg} \cdot \mathrm{ha}^{-1}$;

- $v_{P}$ - the phosphorus content in the soil, $\mathrm{kg} \cdot \mathrm{ha}^{-1}$;

- $v_{4}-$ moisture content in the soil, $\mathrm{mm}$;

- $T_{1} T_{2}$ - time, days in the growing season.

Model (6) in the canonical symbolic vector-matrix form has the following form

$$
\dot{\mathrm{X}}_{m}=\mathrm{A}_{m} \mathrm{X}_{m}(t)+\mathrm{B}_{m} \mathrm{~V}(t)+\mathrm{C}_{m} \mathrm{~F}(t)
$$

in which the structure of vectors and matrices corresponds to the expanded form (6).

\section{A model of the dynamics of parameters of the chemical state and water reserve of the soil}

It reflects the evolution of the parameters of the chemical state and water reserve of the soil in the daily time scale, depending on the main influencing factors. Canonical vector-matrix expanded form of the model

$$
\begin{aligned}
& {\left[\begin{array}{l}
\dot{v}_{\mathrm{N}} \\
\dot{v}_{\mathrm{K}} \\
\dot{v}_{\mathrm{P}} \\
\dot{v}_{4}
\end{array}\right]=\left[\begin{array}{cccc}
a_{11} & 0 & 0 & a_{14} \\
0 & a_{22} & 0 & a_{24} \\
0 & 0 & a_{33} & a_{25} \\
0 & 0 & 0 & a_{44}
\end{array}\right]_{h p}\left[\begin{array}{c}
v_{\mathrm{N}} \\
v_{\mathrm{K}} \\
v_{\mathrm{P}} \\
v_{4}
\end{array}\right]+\left[\begin{array}{cccc}
1 & 0 & 0 & 0 \\
0 & 1 & 0 & 0 \\
0 & 0 & 1 & 0 \\
0 & 0 & 0 & 1
\end{array}\right]_{m}\left[\begin{array}{l}
d_{N}(t) \\
d_{K}(t) \\
d_{P}(t) \\
d_{W}(t)
\end{array}\right]+} \\
& +\left[\begin{array}{ccc}
0 & 0 & c_{13} \\
0 & 0 & c_{23} \\
0 & 0 & c_{33} \\
c_{41} & c_{42} & 1
\end{array}\right]_{p h}\left[\begin{array}{l}
f_{1}(t) \\
f_{2}(t) \\
f_{3}(t)
\end{array}\right]-\left[\begin{array}{cc}
m_{11} & 0 \\
m_{21} & 0 \\
m_{31} & 0 \\
m_{41} & m_{42}
\end{array}\right]_{p h}\left[\begin{array}{l}
x_{1 m}(t) \\
x_{2 m}(t)
\end{array}\right]-\left[\begin{array}{ccc}
n_{11} & 0 & 0 \\
0 & n_{22} & 0 \\
0 & 0 & n_{33} \\
0 & 0 & 0
\end{array}\right]\left[\begin{array}{l}
x_{1 h}(t) \\
x_{2 h}(t) \\
x_{3 h}(t)
\end{array}\right],
\end{aligned}
$$


where $d_{\mathrm{P}}(t), d_{\mathrm{K}}(t), d_{\mathrm{N}}(t), d_{\mathrm{w}}(t)$ - the doses of nutrients, respectively, of phosphorus $\mathrm{P}$, potassium $\mathrm{K}$ and nitrogen $\mathrm{N}, \mathrm{kg} \cdot \mathrm{ha}^{-1}$ and irrigation rate $d_{\mathrm{w}}, \mathrm{mm}$;

$a_{11}-a_{33}, c_{13}-c_{42}, m_{11}-m_{42}, n_{11}-n_{33}$ - model parameters estimated from the experimental data; $t$ is the time, days.

Symbolic vector-matrix form of the model

$$
\dot{\mathrm{X}}_{h}=\mathrm{A}_{h x} \mathrm{X}_{h}(t)+\mathrm{B}_{h x} d_{N v}(t)+\mathrm{M}_{h x} \mathrm{~V}(t)+\mathrm{c}_{h x} f_{2}(t) .
$$

The given system of models makes it possible to implement an algorithm for estimating the state parameters of the entire soil-sowing system using the observed reflection parameters from remote sensing means. At the same time, the dimension of the vector of measured (observed) quantities is 5, and it is less than the dimension of the full vector of state parameters of the entire system, equal to 9. However, modern estimation technologies make it possible to restore estimates of directly unobservable state parameters of multidimensional systems $[25 ; 27 ; 28]$.

\section{General assessment algorithm}

Since the parameters of the chemical state of the soil are inaccessible to remote sensing means, the following iterative scheme for their assessment is proposed. It consists in the fact that based on mathematical models and current remote sensing data, the parameters of the crop biomass are estimated, as well as the parameters of the chemical state of the crop biomass, and estimates of the parameters of the chemical state of the soil are constructed from the estimates obtained. Estimates of the parameters of the chemical state of the soil thus formed are repeatedly substituted into the algorithms for estimating the parameters of the biomass and the parameters of the chemical state of the biomass. Such a procedure is repeated until convergence is achieved, which can be indicated by the proximity of the vectors of real reflection parameters and their estimates for the chemical state of the crop biomass. Based on these comments, the algorithm for estimating the parameters of the chemical state of the soil includes the following steps.

Step 1. Initial assessment conditions are introduced:

- vector of the parameters of the state of the biomass inoculation $\mathrm{X}_{m}(0)$;

- vector of the parameters of the chemical state of the crop $\mathrm{X}_{h}(0)$;

- vector of parameters of the chemical state of the soil $\mathrm{V}(0)$.

Step 2. Enter the data of remote sensing at time t:

- vector of the observed reflection parameters for the state of sowing biomass $Z_{m}(t)$;

- vector of the observed reflection parameters of the chemical state of the crop $Z_{h}(t)$.

Step 3. The sowing biomass parameters are estimated at time $\mathrm{t}$ according to the following procedure $[25 ; 27 ; 28]$

$$
\begin{aligned}
& \dot{\mathrm{X}}_{m}=\mathrm{A}_{m} \hat{\mathrm{X}}_{m}(t)+\mathrm{B}_{m} \hat{\mathrm{V}}(t)+\mathrm{C}_{m} \mathrm{~F}(t)+\mathrm{R}_{m}(t) \mathrm{P} \frac{\partial \mathrm{W}\left(\hat{\mathrm{X}}_{\mathrm{m}}\right)}{\partial \widehat{\mathrm{X}}_{\mathrm{m}}} \mathrm{K}_{z m}^{-1}\left(Z_{m}(t)-\widehat{\mathrm{X}}_{m}(t)\right), \\
& \dot{\mathrm{R}}_{m}=\mathrm{R}_{m}(\mathrm{t}) \mathrm{A}_{m}^{\mathrm{T}}+\mathrm{A}_{m} \mathrm{R}_{m}(\mathrm{t})-\mathrm{R}_{m}(\mathrm{t}) \frac{\partial \mathrm{W}^{\mathrm{T}}\left(\hat{\mathrm{X}}_{\mathrm{m}}\right)}{\partial \hat{\mathrm{X}}_{\mathrm{m}}} \mathrm{K}_{z m}^{-1} \frac{\partial \mathrm{W}\left(\hat{\mathrm{X}}_{\mathrm{m}}\right)}{\partial \widehat{\mathrm{X}}_{\mathrm{m}}} \mathrm{R}_{m}(\mathrm{t}), \\
& \hat{\mathrm{X}}_{m}(0)=\mathrm{X}_{m}(0), \mathrm{R}(0)=\mathrm{K}_{m},
\end{aligned}
$$

where $\mathbf{R}_{m}$ - covariance matrix of estimation errors.

Step 4. The parameters of the chemical state of the sowing biomass at time $t$ are estimated:

$$
\begin{aligned}
& \dot{\mathrm{X}}_{h}=\mathrm{A}_{h x} \hat{\mathrm{X}}_{h}(t)+\mathrm{B}_{h x} d_{N v}(t)+\mathrm{M}_{h x} \hat{\mathrm{V}}(t)+\mathrm{c}_{h x} f_{2}(t)+\mathrm{R}_{h} \mathrm{~K}_{z h}^{-1}\left(Z_{h}(t)-\widehat{\mathrm{X}}_{h}(t)\right), \\
& \dot{\mathrm{R}}_{h}=\mathrm{R}_{h}(t) \mathrm{A}_{h x}^{\mathrm{T}}+\mathrm{A}_{h x} \mathrm{R}_{h}(t)-\mathrm{R}_{h}(\mathrm{t}) \mathrm{K}_{h x}^{-1} \mathrm{R}_{h}(\mathrm{t}), \\
& \hat{\mathbf{X}}_{h}(0)=\mathrm{X}_{h}(0), \mathbf{R}_{h}(0)=\mathrm{K}_{h x},
\end{aligned}
$$

where $\mathrm{R}_{h}$ - covariance matrix of estimation errors.

Step 5. The parameters of the chemical state of the soil are evaluated: 


$$
\begin{aligned}
& \dot{\mathrm{V}}=\mathrm{A}_{h p} \mathrm{~V}(t)+\mathrm{B}_{h p} \mathrm{D}(t)+\mathrm{C}_{h p} F(t)-\mathrm{M}_{h p} \hat{\mathrm{X}}_{m}(t)-\mathrm{N}_{h p} \hat{\mathrm{X}}_{h}(t) \\
& \hat{\mathrm{V}}(t)=V(0) .
\end{aligned}
$$

Step 6. The evaluation quality criterion is calculated

$$
J(t)=\left(Z_{h}(t)-\mathrm{P}_{h} \mathrm{~W}\left(\hat{\mathrm{X}}_{h}\right)\right)^{\mathrm{T}}\left(Z_{h}(t)-\mathrm{P}_{h} \mathrm{~W}\left(\mathrm{X}_{h}\right)\right) .
$$

The current value of the criterion (16) is fixed as $\mathrm{Jt}=\mathrm{J}(\mathrm{t})$ and go to step 3, where estimates of the vector of parameters of the chemical state of the soil are transferred.

Step 7. After repeating steps 3-6, a new criterion value (16) is obtained, which is fixed as $\mathrm{J}_{\mathrm{t}+1}=\mathrm{J}(\mathrm{t})$. If $\mathrm{J}_{\mathrm{t}}-\mathrm{J}_{\mathrm{t}+1} \leq \delta$, then STOP, otherwise go to step 3, until the condition $\mathrm{J}_{\mathrm{t}}-\mathrm{J}_{\mathrm{t}+1} \leq \delta$ is fulfilled.

Since the parameters of the chemical state of the soil are not measured, the algorithm for estimating them (15) has no feedback according to estimates, i.e. it is not closed. Therefore, the control criterion of the general estimation algorithm is closed by the measured parameters of the chemical state of the crop. Another variant of the general algorithm scheme is possible, which can be called classical $[25 ; 27 ; 28]$.

It implies combining all considered models into a single model of the "soil-sowing" system, which contains a block of optical measurements (RS) and a block of dynamics of state parameters. In this case, immediately at one time, a vector of assessments of the entire system is formed, including the parameters of the chemical state of the soil. However, this variant of the algorithm is difficult to implement due to the separate identification of models of individual system blocks and the construction of a common matrix of covariance errors of optical measurements of the state parameters of these elements.

\section{Testing the evaluation algorithm}

Stage 1. Periodically, with an interval of 7-10 days, samples are taken from test sites, the area of each is $25-30 \mathrm{~m}^{2}$ and the number is $12-15$ pcs. Of the following system status parameters:

- parameters of the state of sowing biomass: $x_{1 m}$ is the average density of the sowing biomass over the field area (yield), $\mathrm{kg} \cdot \mathrm{m}^{-2} ; x_{2 m}$ is the average density of the dry sowing mass over the field area;

- parameters of the chemical state of the crop biomass: $x_{1 h}, x_{2 h}, x_{3 h}$ - respectively, the content of nitrogen, potassium and phosphorus;

- parameters of the chemical state of the soil: $v_{\mathrm{N}}$ is the nitrogen content in the soil, $v_{\mathrm{K}}$ is the potassium content in the soil, $v_{\mathrm{P}}$ is the phosphorus content in the soil, $v_{4}$ is the moisture content in the soil.

Available means of remote sensing over the entire surface of the field, including test sites, every three days receive the following remote sensing data:

- reflection parameters of the state of sowing biomass: in the visible range $\left(z_{1}\right)$ and in the infrared range $\left(z_{2}\right)$;

- reflection parameters of the parameters of the chemical state of the crop biomass: $z_{1 h}, z_{2 h}, z_{3 h}-$ reflection parameters in the visible and infrared ranges of the spectrum.

From the nearest meteorological station daily data on external climatic disturbances are received:

- $f_{1}$ - average daily air temperature, ${ }^{\circ} \mathrm{C}$;

- $f_{2}$ - average daily radiation level, $\mathrm{W} \cdot\left(\mathrm{m}^{2} \cdot \mathrm{h}\right)^{-1}$,

- $f_{3}$ - average daily rainfall, $\mathrm{mm}$;

The parameters of control actions are recorded over the entire area of the field and for each test site:

- $d_{P}, d_{K}, d_{C a}, d_{N}$ - the dose of nutrients, respectively, of phosphorus $\mathrm{P}$, potassium $\mathrm{K}$, nitrogen $\mathrm{N}$;

- $d_{N v}$ - doses of foliar top dressings with nitrogen, doses of foliar top dressings with nitrogen;

- $d_{4}$-irrigation rates. 
Stage 2. Based on the operational information obtained by sampling and measuring external disturbances and controls, the parameters of models (3), (5), (7), (10), and (12) are refined. Moreover, the identification time interval is variable, starting from the third measurement to the current time instant $\tau=3.4, \ldots t$.

Stage 3. According to the results of identification of mathematical models (3), (5) and current remote sensing data $Z_{m}(t)$ and external climatic disturbances $\mathrm{F}(\mathrm{t})$, algorithm (13) estimates the vector of parameters of the state of sowing biomass for each current point in time $t$.

Stage 4. According to the results of identification of mathematical models (5), (12) and current remote sensing data $Z_{h}(t)$ and external climatic disturbances $F(t)$, using algorithm (14), estimates of the vector of chemical parameters of the sowing biomass state are formed for each current time $t$.

Stage 5. Based on the results of identification of the mathematical model (10) and the estimates obtained in stages 3,4 , using the algorithm (15), estimates of the vector of parameters of the chemical state of the soil are formed for each current time $t$. At the same time, at the first assessment step, the initial value of the assessment vector is taken equal to the average value of the vector measured at the test sites.

Figures 4 and 5 present the results of identification of mathematical models (3), (5) of remote sensing for mass and chemical parameters of sowing of perennial grasses according to the experimental data from 2016-2019.

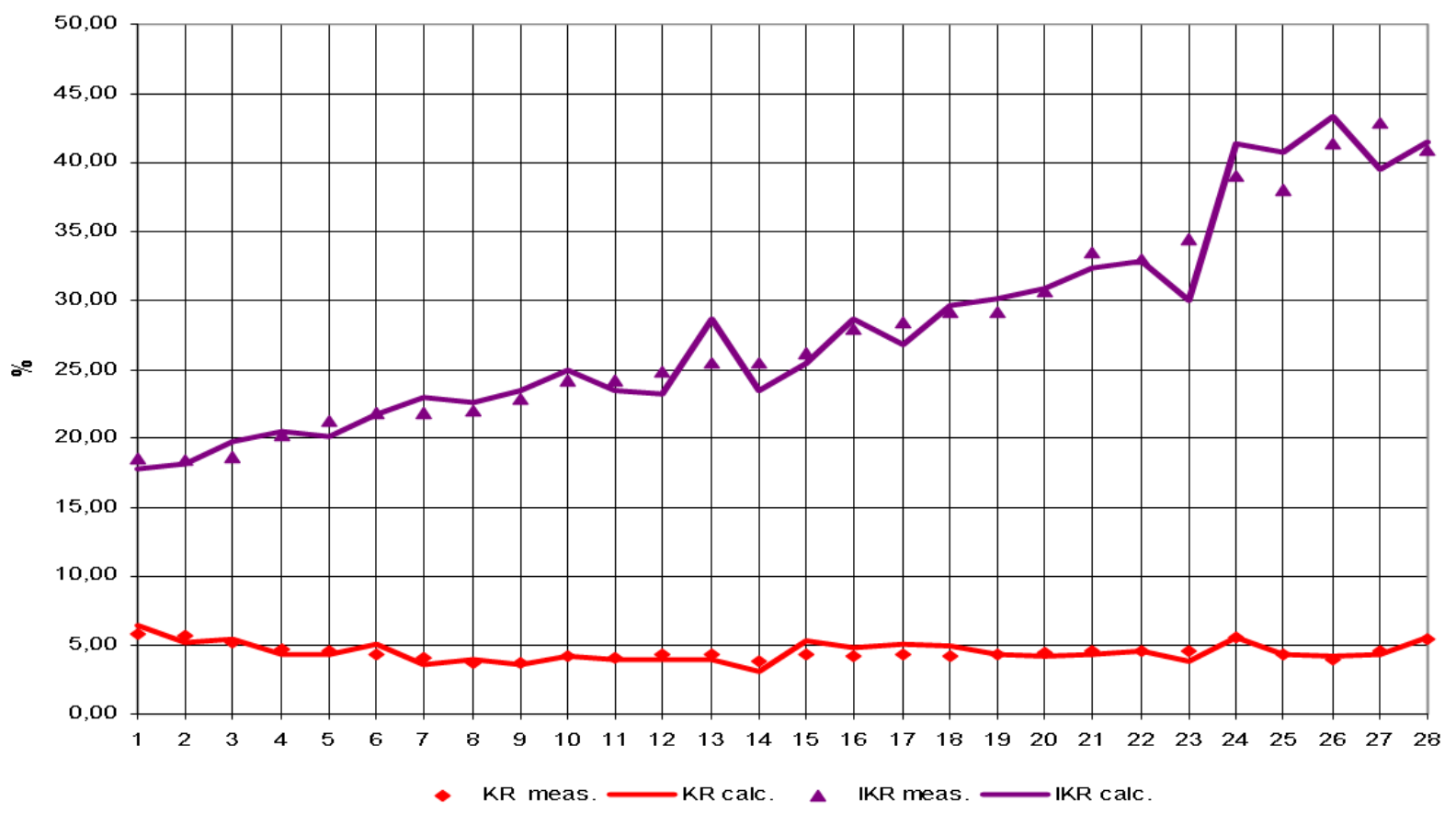

Fig. 4. Results of the identification of mathematical models of remote sensing for mass indicators of sowing perennial grasses

Here, the reflection parameters are reflected along the vertical axis, and the numbers of experimental points are plotted along the horizontal axis, with a different combination of mass indicators and chemical parameters of the crop biomass. This allows us to present the results of identification of a multidimensional model on a single graph. The graphs of the 12-day observation interval show that these models have the properties of regularity and sufficient accuracy. This allows them to be used in problems of estimating state parameters according to remote sensing data.

Figure 6 presents the results of identifying model (7) and evaluating the mass indices of sowing perennial grasses using current remote sensing data and meteorological parameters. Obviously, both the model identification process (calculated values) and the estimation procedure are stable. In this case, the standard error of the estimation is less than the identification error by 30-35\%. It should be noted that estimates of biomass indicators are based only on current remote sensing data, and experimental points on the graph are highlighted to calculate real estimation errors. 


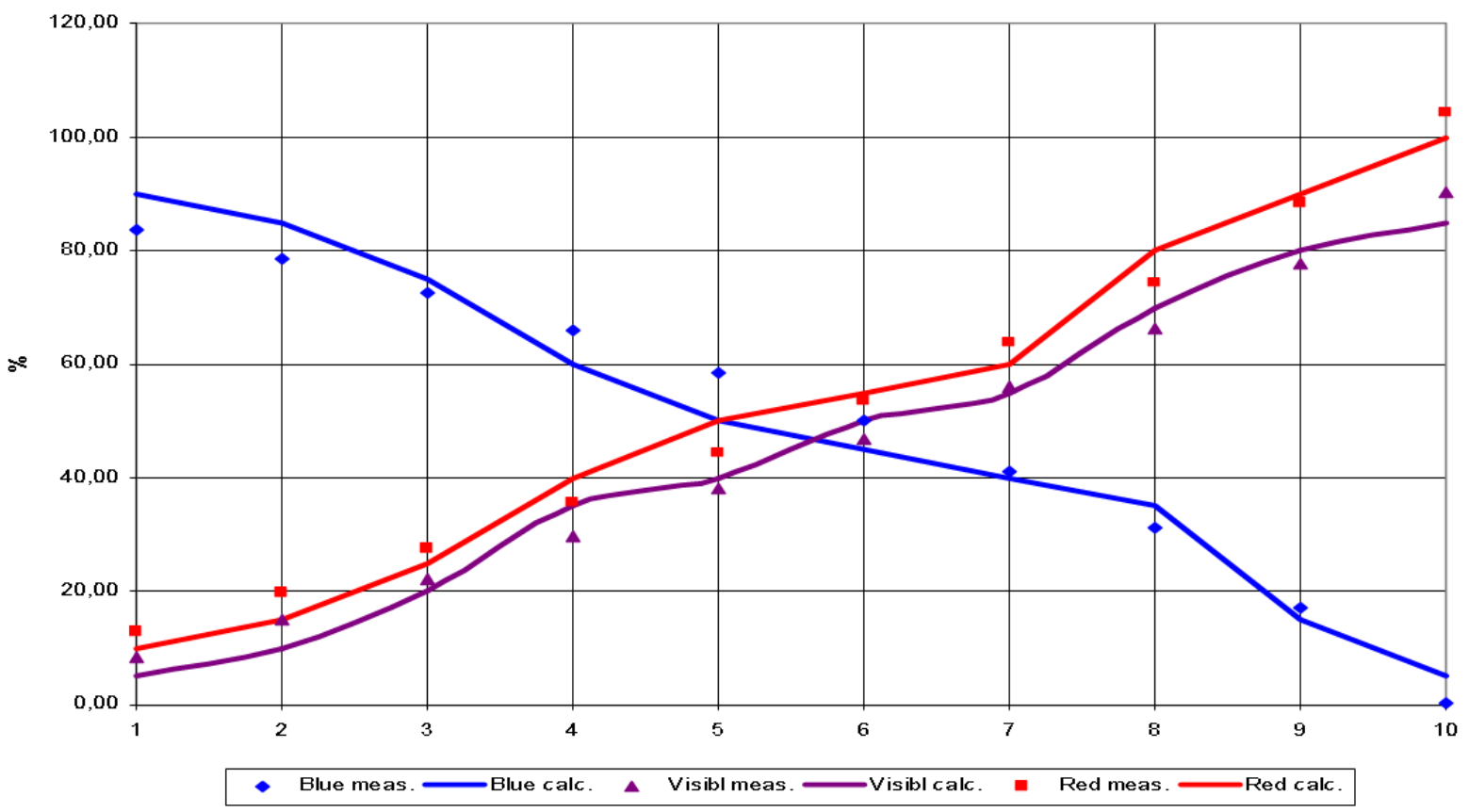

Fig. 5. Results of the identification of mathematical models of remote sensing for the chemical parameters of the biomass of sowing perennial grasses

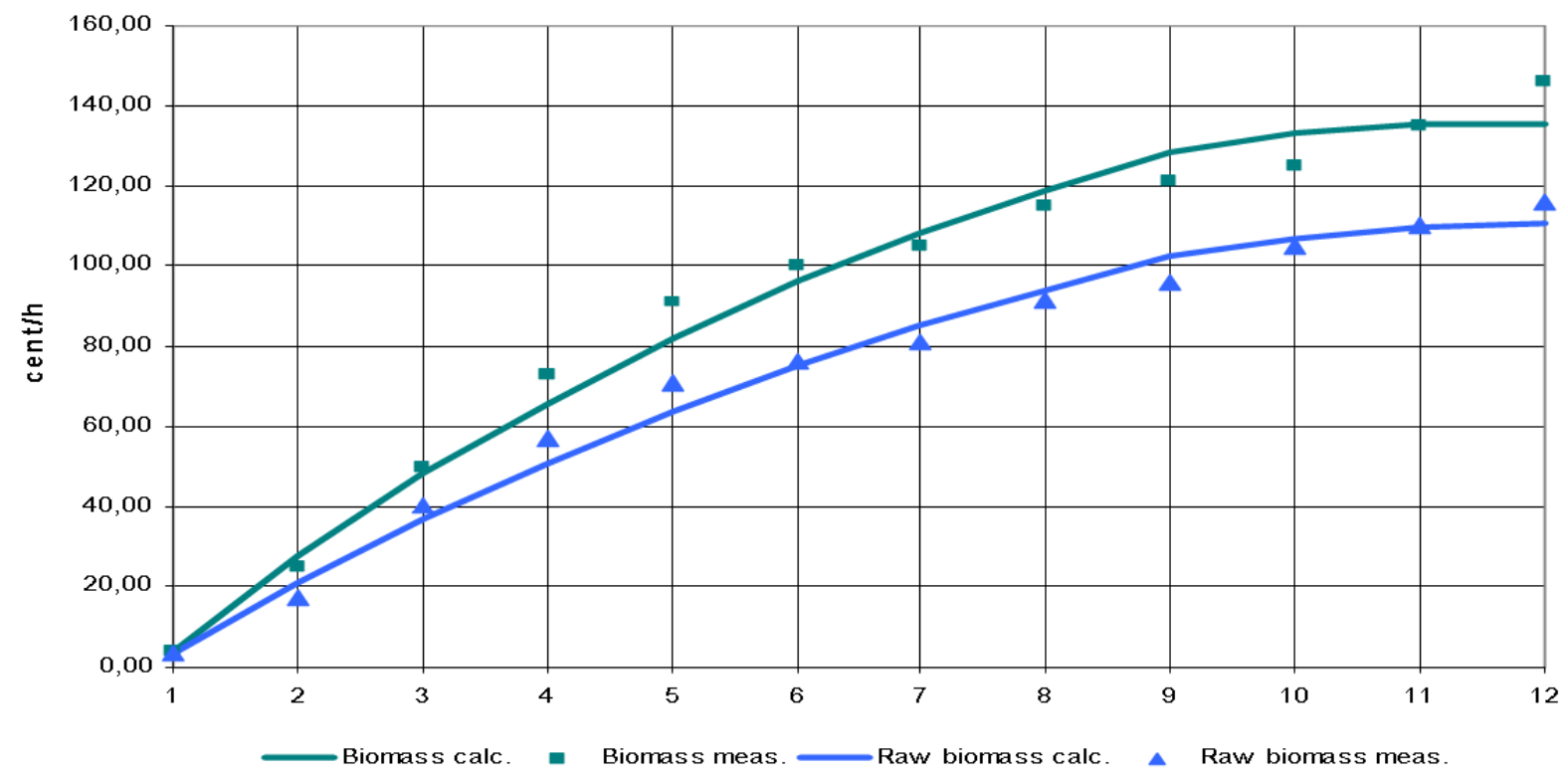

Fig. 6. Results of the identification of the model and the estimation of mass indicators for sowing perennial grasses

Figure 7 presents the main result of the functioning of the entire complex - the process of constructing estimates of the chemical parameters of the soil and its water supply. These estimates are formed on the basis of estimates of mass indicators and chemical parameters of the soil, current meteorological factors and technological operations performed. Here, the experimental parameter points are plotted to calculate the actual estimation errors, which fall within the range of 10-15\%. 


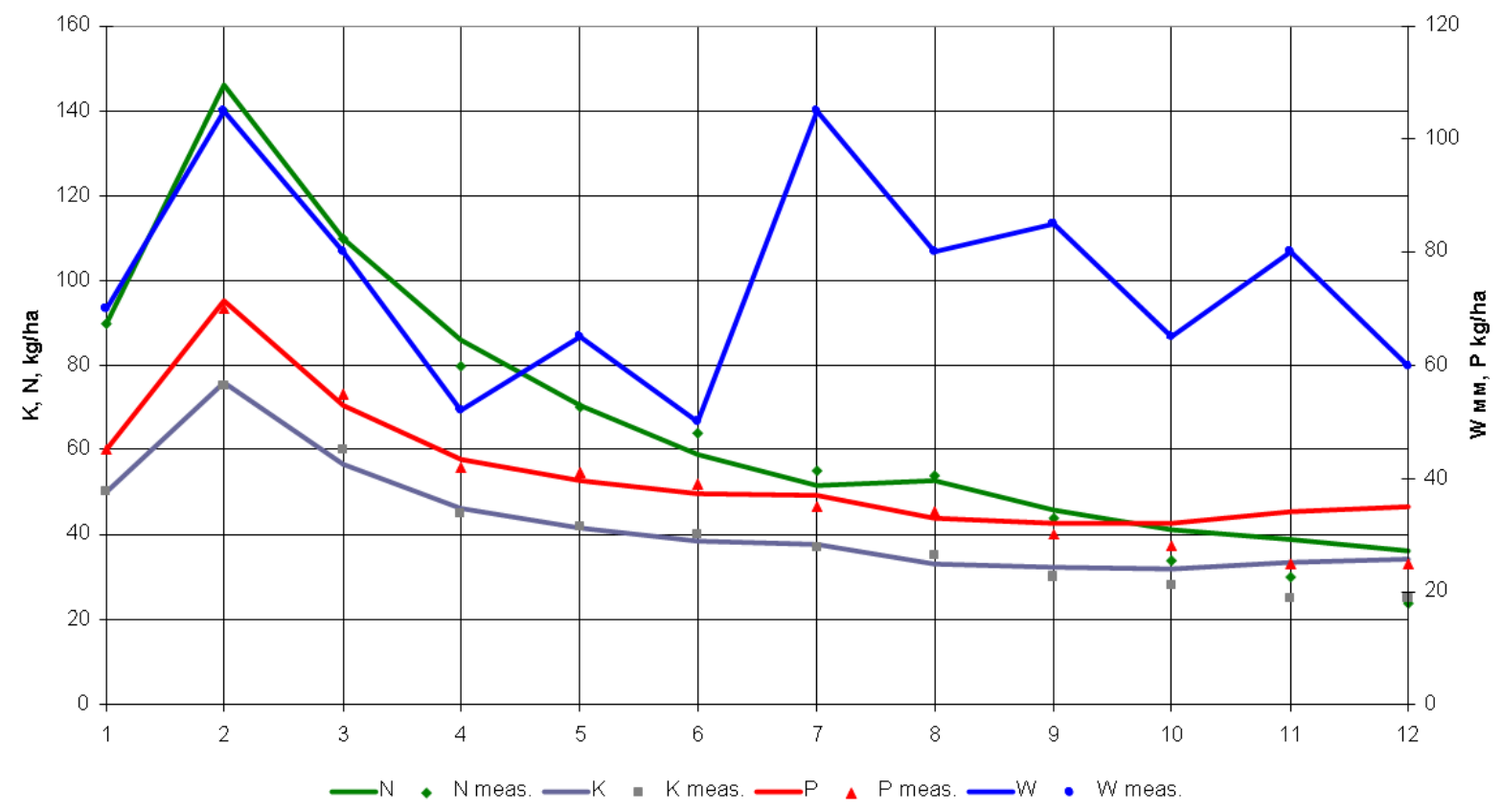

Fig. 7. Results of the evaluation of the chemical parameters of the soil according to remote sensing data

\section{Conclusions}

The methodology and software and hardware tools for assessing the state parameters of crops and soil based on the integration of ground measurements and remote sensing data of the Earth are proposed. The novelty of the proposed methodology is a two-stage iterative assessment procedure, which provides for the sequential assessment of mass indicators of sowing, chemical parameters of sowing and, based on them, the formation of estimates of chemical parameters and water reserve of the soil. To implement the assessment procedure, a set of new mathematical models is used, which includes models of optical measurements by remote sensing, a model of the dynamics of mass indicators of sowing, a model of the dynamics of chemical parameters of biomass, and a model of the dynamics of chemical parameters and soil water supply. The stability and reliability of the estimation procedure is ensured by closing the algorithm through estimating the parameters of the chemical state of the biomass of the crop, which are compared with the actual values of the remote sensing data. The information generated by the assessment complex can be used to make management decisions on the doses of mineral fertilizers and irrigation rates in precision farming systems.

\section{Acknowledgements}

This work was partially supported by the RFBR grant No. 18-016-0008.

\section{References}

[1] МихайленкоИ. М. Управление системами точного земледелия (Mikhailenko I. М. Management of precision farming systems)St. Petersburg: St. Petersburg University, 2005, 223 p. (In Russian).

[2] ред. Д. Шпаар, А.В. Захаренко, В.П. Якушев Точное сельское хозяйство (Ed. D. Shpaar, A. V. Zakharenko, V. P. YakushevPrecision Agriculture), SPb: VIZR, 2009, 397 p.

[3] Кочубей С. М., Шадчина Т. М., Кобец Н. И. Спектральные свойства растений как основа методов дистанционной диагностики (Kochubey S. M., Shadchina T. M., Kobets N. I. Spectralproperties of plantsas the basis of remote diagnostic methods) Kiev: Naukova Dumka. 1990.134 p. (In Russian).

[4] ЧерепановА. С. Вегетационные индексы: справочные материалы (Cherepanov A. S. Vegetation indices: reference materials) Geomatics, No 2, 2011, pp. 98-102. (In Russian).

[5] Антонов В. Н., Сладких Л. А. Мониторинг состояния посевов и прогнозирование урожайности яровой пшеницы по данным ДЗ3 (Antonov V.N., Sladkikh L.A. Monitoring of 
the state of crops and forecasting the yield of spring wheat according to remote sensing data) Geomatics, No. 4, 2009, pp. 50-53. (In Russian).

[6] Барталев С. А., Лупян Е.А., Нейштадт И.А., Савин И.Ю. Классификация некоторых типов сельскохозяйственных посевов в южных регионах России по спутниковым данным MODIS (Bartalev S.A., Lupyan E.A., Neishtadt I.A., SavinI.Yu. Classification of some types of agricultural crops in the southern regions of Russia according to MODIS satellite data) Exploration of the Earth from space, No. 3, 2006, pp. 68-75. (In Russian).

[7] Crippen R.E. Calculating the Vegetation Index Faster. Remote Sensing of Environment, vol. 34, 1990, pp. 71-73.

[8] Lawrence R. Comparisons among Vegetation Indices and Band wise Regression in a Highly Disturbed, Heterogeneous Landscape: Mount St. Helens, Washington. Remote Sensing of Environment, Vol. 64, 1998, pp. 91-102.

[9] Tilly N., Aasen H., Bareth G. Fusion of plant height and vegetation indices for the estimation of barley biomass. Remote Sensing, No. 7(9), 2015, pp. 11449-11480.

[10]Hill M. O., Carey P. D. Prediction of yield in the Rothamsted Park Grass Experiment by Ellenberg indicator values, Journal of Vegetation Science, Vol. 8, 1997, pp. 579-586.

[11] Harmoney K.R., Moore K.J., George I.R. et al. Determination of pasture biomass using four indirect methods. Agronomy Journal, No. 89, 1997, pp. 665-672.

[12] Marshall M.; Thenkabail P. Developing in situ Non-destructive estimates of crop biomass to address issues of scale in Remote Sensing. Remote Sensing, No. 7, 2015, pp. 808-835.

[13]Reddersen B.; Fricke T.; Wachendorf M. A multi-sensor approach for predicting biomass of extensively managed grassland. Computer Electronics Agriculture, No. 109, 2014, pp. 247-260.

[14] Quemada M., Gabriel J., Zarco-Tejada P. Airborne hyperspectural images and ground-level optical sensors as assessment tools for maize nitrogen fertilization. Remote Sensing, No. 6, 2014, pp. 2940-2962.

[15]Zarco-Tejada P. J., Guillén-Climent M. L., Hernández-Clemente R., Catalina A.; González M. R., Martín P. Estimating leaf carotenoid content in vineyards using high resolution hyperspectral imagery acquired from an unmanned aerial vehicle (UAV).Agricultural and Forest Meteorology, Vol. 171-172, 2013, pp. 281-294.

[16] Mulla, D. J. Twenty five years of remote sensing in precision agriculture: Key advances and remaining knowledge gaps. Biosystem Engineering, No. 114, 2012, pp. 358-371.

[17] Oliver M., Bishop T., Marchant B. An overview of precision agriculture. In Precision Agriculture for Sustainability and Environmental Protection. Eds. Routledge: London. UK, 2013, pp. 3-19.

[18] Akhtman Y.,Golubeva E., Tutubalina O., Zimin M. Application of hyperspectural images and ground data for precision farming, Geography, environment, sustainability, 2017, pp. 117-128.

[19] Jaud M., Le Dantec N., Ammann J., Grandjean P., Constantin D., Akhtman Y., Barbieux K., Allemand P., Delacourt C., Merminod B. Direct Georeferencing of a Pushbroom, Lightweight Hyperspectral System for Mini-UAV Applications. Remote Sensing, No. 10(2), 2018, pp. 204219.

[20] Михайленко И. М. Стратегический уровень управления в системах точного земледелия. (MikhaylenkoI.M. Strategic level of management in precision farming systems) Agrophysics, No. 3, 2014, pp. 25-34. (InRussian).

[21] Михайленко И. М., Тимошин В.Н. Оптимизация управления химическими параметрами почв в полевых севооборотах. (Mikhailenko I.M., Timoshin V.N. Optimization of control of chemical parameters of soils in field crop rotations), Agrochemistry, No. 3, 2016, pp. 3-10. (In Russian).

[22] Михайленко И. М., Тимошин В.Н. Управление химическими параметрами почв на основе данных дистанционного зондирования Земли. (Mikhailenko I.M., Timoshin V.N. Management of chemical state of soils based on remote sensing data of the Earth), Taurian herald of agrarian science, No. 1(13), 2018, pp. 65-76. (In Russian).

[23] Hyperspectural imagine and big data in agricultural. Report on Kayapo Farm. June 2015. https://gamaya.com.

[24]Рачкулик В.И., Ситникова М.В. Отражающие свойства и состояние растительности (Rachkulik V.I., Sitnikova M.V. Reflective properties and state of vegetation). Leningrad: Hydrometeoizdat, 1981. 287 p. (In Russian). 
[25]Михайленко И.М. Основные задачи оценки состояния посевов и почвенной среды по данным космического зондирования (MikhaylenkoI.M. The main task so assessing the state of crop sand the soil environment according to spaces ensign data). Ecological Systems and Devices, No. 8, 2011, pp. 17-25. (In Russian).

[26]Михайленко И. М., Курашвили А. Е. Прогнозирование состояния травостоя в системе управления качеством кормов в молочном животноводстве (Mikhailenko I. M., Kurashvili A. E. Prediction of the state of grassland in the feed quality management system in dairy farming) Bulletin of the RSHA. No. 2, 2008, pp. 10-13. (In Russian).

[27]Казаков И. Е. Методы оптимизации стохастических систем (KazakovI. Ye. Methods for optimization of stochastic systems). Moscow: Science, 1987. 348 p. (In Russian).

[28] Mikhailenko I. M. Assessment of crop and soil state using satellite remote sensing data. International Journal of Information Technology \& Operations Management, Vol.1, № 5, 2013, pp. 41-52. 